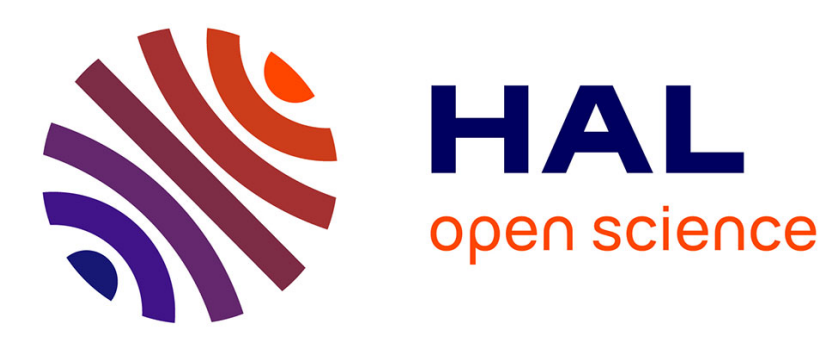

\title{
Volume Variation in Stretched Natural Rubber: Competition between Cavitation and Stress-Induced Crystallization
}

Jean-Benoit Le Cam, Evelyne Toussaint

\section{- To cite this version:}

Jean-Benoit Le Cam, Evelyne Toussaint. Volume Variation in Stretched Natural Rubber: Competition between Cavitation and Stress-Induced Crystallization. Macromolecules, 2008, 41, pp.7579-7583. 10.1021/ma801290w . hal-01131586

\section{HAL Id: hal-01131586 \\ https://hal.science/hal-01131586}

Submitted on 16 Mar 2015

HAL is a multi-disciplinary open access archive for the deposit and dissemination of scientific research documents, whether they are published or not. The documents may come from teaching and research institutions in France or abroad, or from public or private research centers.
L'archive ouverte pluridisciplinaire HAL, est destinée au dépôt et à la diffusion de documents scientifiques de niveau recherche, publiés ou non, émanant des établissements d'enseignement et de recherche français ou étrangers, des laboratoires publics ou privés.

\section{(ㄷ)(1)}

Distributed under a Creative Commons Attribution| 4.0 International License 


\title{
Volume variation in stretched natural rubber: competition between cavitation and stress-induced crystallization
}

\author{
J-B. Le Cam*, E. Toussaint \\ Laboratoire de Mécanique et Ingénieries (LaMI), Université Blaise Pascal - Institut Français de \\ Mécanique Avancée, Campus de Clermont-Ferrand les Cézeaux, BP 265, 63175 Aubière Cedex, France
}

\begin{abstract}
The present paper deals with the competition between cavitation and stress-induced crystallization during the deformation of cis-1,4 polyisoprene rubber. During deformation, this kind of material exhibits volume variation induced by both phenomena. In this study, we propose to measure this volume variation by an original full-field measurement technique. The high resolution of this technique allows us to identify characteristic stretch ratios during mechanical cycles. More especially, the competition between cavitation and stress-induced crystallization is discussed related to stretch ratios at the beginning of crystallization and at the end of crystallite melting. Moreover, the addition of fillers significantly influences the volume variation response. They amplify the cavitation phenomenon and allow the crystallization to begin at a lower stretch ratio. Results obtained with filled compound under cyclic loading conditions show that relative volume change is stabilized for a lower number of cycles than the stress-stretch response and that the crystallinity seems to be lower than for unfilled natural rubber. Finally, for the applied strain rate, the Mullins effect is found to have no influence on the value of stretch ratios at the beginning of crystallization and at the end of crystallite melting.
\end{abstract}

KEYWORDS. natural rubber / volume variation / stress-induced crystallization / cavitation 


\section{Introduction}

The physical mechanisms involved during the deformation of rubbers are not clearly understood and are still the object of a vivid scientific debate. At small deformations, experimental and theoretical studies have shown that cavitation occurs in the bulk material. ${ }^{1-3}$ From a mechanical point of view, voids and cavities can be considered as damage which increases with deformation. At large deformations, the polymer chain network evolves and stress-induced crystallization can occur. ${ }^{4}$ As fillers are added, the mechanical response is strongly influenced in the deformation range of the Payne effect ${ }^{5}$, as well as in the large deformation range. Moreover, the strain concentration in the filler vicinity is favorable to crystallization. ${ }^{6}$ These previous results seem to indicate that the occurrence and growth of cavities and stress-induced crystallization are the main phenomena involved in the deformation of crystallizable rubbers.

In the past, both phenomena have previously been investigated by measuring volume variation. In the case of cavitation, the relative volume change $\frac{\Delta V}{V}$ is classically described versus the elongation $\lambda$ (defined as the ratio between the current length and the initial length) during one mechanical loading. ${ }^{7-11}$ In the case of stress-induced crystallization, studies have investigated the volume decrease due to the chain crystallization versus time. ${ }^{12}$ Results show that the time necessary to observe volume variation decreases as the prescribed initial deformation increases. More recently, crystallinity has been measured by in-situ synchrotron X-rays in the case of uniaxial deformation, ${ }^{13-17}$ but this technique does not allow us to provide quantitative information on volume changes. To our knowledge, the work of Mullins and Tobin $^{7}$ was the first experimental work that has shown that, in the case of natural rubber extension, crystallization can induce a significant volume decrease at large deformations. However, no study is dedicated to describing simultaneously the competition between the former phenomenon and cavitation.

The present paper focuses on the description of the competition between both phenomena during deformation of natural rubber. As cavitation involves volume increase and as stress-induced 
crystallization involves volume decrease, volume variation seems to be the most appropriate experimental measurement to describe simultaneously the abovementioned physical phenomena. For that purpose, a full field measurement method based on image correlation is used to determine the volume variation from displacement of material points on the samples' surface. First, the volume variation in unfilled natural rubber is investigated during one uniaxial mechanical cycle. Then, the influence of fillers on the volume variation and on the competition between cavitation and stressinduced crystallization is discussed. Finally, the stabilization of cyclic volume variation is studied in relation with the stabilization of the stress-stretch response.

\section{Experimental Section}

2.1 Materials and samples. All the samples contain $3 \mathrm{~g}$ stearic acid, $9.85 \mathrm{~g}$ zinc oxide, $2 \mathrm{~g}$ antioxidant, $3 \mathrm{~g}$ sulphur, $3 \mathrm{~g}$ oil and $4 \mathrm{~g}$ accelerators, per $100 \mathrm{~g}$ of natural rubber. Some of them are filled with carbon black (34 g per $100 \mathrm{~g}$ of natural rubber). The unfilled compound is heated to $160^{\circ} \mathrm{C}$ for 10 minutes, the filled compound is heated to $160^{\circ} \mathrm{C}$ for 7 minutes. In the following, unfilled and filled compounds will be referred to as NR and F-NR respectively. The degree of crosslinking, characterized by the number $v$ of moles of crosslinks per g, was estimated using the Mooney elastic coefficient $C_{1}$, determined from experimental relations between tensile nominal stress $\pi$ (force per unit of unstrained cross-sectional area) and stretch ratio $\lambda$ :

$$
\frac{\pi}{2\left(\lambda-\lambda^{-2}\right)}=C_{1}+\frac{C_{2}}{\lambda}
$$

From the simple kinetic theory of rubber elasticity: ${ }^{18}$

$$
v=2 \frac{C_{1}}{R T}
$$

where $R$ is the gas constant and $T$ is absolute temperature. In the case of unfilled compound, $v$ is found to be equal to $11.3 \mathrm{~mol} / \mathrm{g} \times 10^{-5}$. To overcome aging problems, samples are frozen at $-18^{\circ} \mathrm{C} 48 \mathrm{~h}$ after their molding. They are then thawed out 24 hours before testing. The sample dimensions are $30 \times 4 \mathrm{~mm}^{2}$ 
and $2 \mathrm{~mm}$ thick.

2.2 Loading conditions. Mechanical cycles are performed at room temperature $\left(23^{\circ} \mathrm{C}\right)$ and $34 \%$ hygrometry under prescribed displacement with a $50 \mathrm{~N}$ Instron 5543 testing machine. The corresponding stretch ratio varies between 1 and 4.7 for unfilled NR samples and between 1 and 2.55 for filled NR samples. The strain rate is set to $1.3 \mathrm{~min}^{-1}$ for each test.

2.3 Volume variation measurement. The change in volume is deduced from the displacement fields on the sample surface obtained by the image correlation technique. It consists in correlating the grey levels between two different images of a given zone. Each image corresponds to different stretch ratio levels. To improve the image contrast, suitable white paint is sprayed on the surface before testing samples. This leads to a black and white random gray field. This optical technique allows us to reach a resolution of 0.1 pixel corresponding to $5.9 \mu \mathrm{m}$ and a spatial resolution (defined as the smallest distance between two independent points) of 10 pixels corresponding to $590 \mu \mathrm{m}$. The software used for the correlation process is SeptD. ${ }^{19}$

Figure 1 presents the overall view of the optical setup. It consists in a cooled 12-bit dynamic Sensicam camera connected to a personal computer in order to process image acquisition and data treatment with the SeptD software. A uniform light at the sample's surface is ensured by lamps. The charge-coupled device (CCD) of the camera has $1.410^{6}$ joined pixels (1376 x 1040). The camera is fixed on a multidirectional adjustable support and the distance between the sample and the CCD matrix is about $60 \mathrm{~cm}$. In this configuration, an area of $4 \times 81 \mathrm{~mm}^{2}$ is within shot of the digital camera. The size of this zone is sufficient to calculate global displacement slopes in both horizontal and vertical directions.

The previous full-field measurements are now considered to calculate the volume variation of the samples at each step of loading. For each mechanical cycle test, 36 and 28 images are stored for NR and F-NR respectively. The first image is the reference one and corresponds to the undeformed state. The other images correspond to successive deformed states. Because of the large deformations undergone by 
the material, the displacement fields for each deformed state cannot be calculated by correlating images from the reference image. Thus, the following method has been developed:

(i) two successive images are correlated and relative displacement fields are calculated with SeptD software. Between two images, a displacement of $3 \mathrm{~mm}$ is imposed by the moving grip. Then, relative displacement slopes in the horizontal and vertical directions are determined from Matlab software. In the present work, the material behavior is assumed to be transversely isotropic. This assumption has been checked from displacement calculated on the front and the side faces of the samples. So, relative stretch ratios and relative volume change can be calculated.

(ii) finally, stretch ratios and volume variations are obtained by successive multiplications of the relative ones. This method has been validated by correlating the reference image and the last one of the cycle.

\section{Results}

First of all, volume variation measurements are presented for NR during the first mechanical cycle. Secondly, similar measurements are carried out with F-NR to determine the influence of carbon black fillers on volume variation, i.e. on cavitation and on stress-induced crystallization. Finally, volume variations in the filled compound obtained under three cycles are presented and discussed in relation with the well-known stress softening occurring during the first cycles in such a material. ${ }^{20}$ It should be noted that each result presented in the present section has been validated by two other tests.

3.1 Volume variation in NR. Figure 2(a) presents the stress-stretch response of the material obtained during the first mechanical cycle and Figure 2(b) the corresponding volume variation. Figure 2(b) shows that the relative volume variation does not exceed $6.10^{-2}$ during the cycle. Here, the curve obtained can be modeled by four segments ([OA], $[\mathrm{AB}],[\mathrm{BC}]$ and $[\mathrm{CD}]$ ). The competition between cavitation and stress-induced crystallization can be described in relation with each segment: 

reported in the literature, cavitation takes place around zinc oxide particles and at the poles of metallic oxide inclusions. ${ }^{21}$ The higher the stretch level, the higher the size of cavities.

(ii) segment $[\mathrm{AB}]$ : from $\lambda_{A}=4.2$, the volume begins to decrease. Even if cavities continue to appear and grow, another phenomenon tends to reduce the volume. In fact, volume decrease in NR is well-known to be due to the reorganization of the polymer chain under stress, namely stress-induced crystallization. ${ }^{4,12}$ This phenomenon is of the first order compared to cavitation. Moreover, this phenomenon also induces stress relaxation in the amorphous phase of the rubber previously described by numerous authors. ${ }^{22}$

(iii) segment $[\mathrm{BC}]$ : during the unloading, the sample volume at a given stretch ratio is smaller than during loading. This can be due to either the difference between the kinetics of crystallization and of crystallite melting or the anelastic deformation of cavities. To investigate the deformation of cavities, volume change is measured over one cycle for which the maximum stretch ratio is still inferior to $\lambda_{A}$, i.e. the stretch ratio at which crystallization is initiated. Figure 3(a) presents the stress-stretch curve obtained. The fact that the hysteresis loop is very small indicates that no crystallization occurs in the bulk material. ${ }^{6}$ Figure $3(\mathrm{~b})$ shows that the volume change is the same for loading and unloading. This indicates that cavitation generated under such loading conditions can be considered as an elastic process. The kinetics of crystallization and crystallite melting can be studied by stopping the displacement of the moving grip during the mechanical cycle. Here, the moving grip is stopped for 1 minute every $3 \mathrm{~mm}$ during the third mechanical cycle, i.e. a stabilized mechanical cycle. The results are presented in Figure 4. During the stops, stress relaxes for the loading but does not increase for unloading. That proves that contrary to crystallization, crystallite melting is instantaneous. Thus, crystallization initiated at a given stretch ratio continues during the extension test at a greater stretch ratio. This is in good agreement with the recent works of Trabelsi. ${ }^{6}$ These 
results prove that the hysteresis loop obtained for volume change curves is only due to chain crystallization. To finish, point $\mathrm{C}$ corresponds to the melting of the last crystallites.

(iv) segment [CD]: the volume slightly decreases when the cavities close.

To summarize the previous results, relative volume variation does not exceed $6.10^{-2}$ in NR. No significant residual volume change is observed. This indicates that the deformation of cavities is an elastic process. This in turn shows that cavitation, i.e. volume increase, does not take part into the residual stretch obtained after the first mechanical cycle. Competition between cavitation and crystallization has been highlighted. More particularly, crystallization is a first order phenomenon and tends to reduce the volume of the material even though cavities continue to grow. The difference in kinetics between crystallization and crystallite melting, more particularly, the fact that, contrary to crystallization, crystallite melting is an instantaneous phenomenon, explains that for a given stretch ratio, the volume variation is lower during unloading than during loading. The elongation at the beginning of crystallization and at the end of crystallite melting are found to be equal to 4.2 and 2, respectively.

3.2 Influence of fillers. The previous material has been filled with $34 \mathrm{~g}$ of carbon black (N326) per $100 \mathrm{~g}$ of natural rubber. The sample's geometry remains the same as for NR. One cycle is performed under prescribed displacement. The maximum stretch ratio reached during the cycle is equal to 2.55 . The stress-stretch response of the material obtained during the first mechanical cycle is presented in Figure 5(a). As expected, fillers increase the material rigidity. Figure 5(b) gives the corresponding volume variation. In this figure, the relative volume variation reaches $24.10^{-2}$ at a maximum stretch ratio equal to 2.55. As explained above, fillers amplify the cavitation and the decohesion phenomena. They also amplify the strain. ${ }^{13}$ The obtained volume variation curve can be modeled by five segments ([OA], [AB], [BG], [GC] and [CD]). Similarly to the previous result, characteristic stretch ratios $\left(\lambda_{A}\right.$ and $\left.\lambda_{C}\right)$ are observed in this curve and a new characteristic stretch ratio $\lambda_{G}$ is also observed. Thus, it is possible to describe the competition between cavitation and stress-induced crystallization related to each segment: 
(i) segment [OA]: from zero deformation, the volume increases due to the occurring and growth of cavities.

(ii) segment $[\mathrm{AB}]$ : from $\lambda_{A}=1.64$ the curve slope is lower than for segment [OA]. In fact, even if cavities grow continuously, cavitation is still a first order phenomenon due to the addition of fillers, crystallization begins and is opposite to the volume increase. The fact that crystallization occurs at a lower stretch ratio than for NR is explained by the presence of fillers which amplify the local deformation.

(iii) segment [BG]: at the beginning of the unloading, the volume decreases as the cavity size decreases and the melting of crystallites starts. Similarly to the unfilled compound, the crystallinity level obtained during unloading is superior to the one obtained in loading for a given stretch ratio and the volume variation is inferior during unloading.

(iv) segment [GC]: the volume of cavities continues to decrease, and crystallites continue to melt, but with a higher rate. Consequently, the rate of volume variation is inferior;

(v) segment [CD]: melting of crystallites is complete, and the volume decrease is only due to cavities closing.

To summarize, the addition of fillers increases the volume variation. The fact that from $\lambda_{A}=1.64$ the volume variation does not decrease as in NR indicates that, even if the elongation at crystallization is lower than in NR, the addition of fillers tends to minimize the level of crystallinity for a given stretch ratio. This is the reason why the hysteresis loop is smaller in F-NR than in NR. This is in good agreement with the results of Trabelsi et al. ${ }^{13}$ Finally, the influence of the kinetics of stress-induced crystallization on volume variation in both NR and F-NR can be summarized by the diagram in Figure 6.

3.3 Volume variation during cyclic loadings. To investigate the volume variation obtained during cyclic loading, three mechanical cycles were performed. Figure 7(a) presents the stress-stretch response and Figure 7(b) the corresponding volume variation. The second figure shows that the 
highest of relative volume change and of hysteresis area are reached during the first cycle. During the second and the third cycles, these quantities are lower. Contrary to the stress-stretch response, the volume variation is stabilized after the first cycle. This result shows that cavitation and decohesion are not preponderant phenomena involved in the Mullins effect. ${ }^{20}$ Moreover, from the third cycle presented in Figure 8, the same characteristic stretch ratios as those of the first cycle are observed: crystallization starts at $\lambda=1.64$ and the last crystallites melt at $\lambda=1.44$.

\section{Conclusion}

Volume variation measurements performed in both unfilled and filled natural rubber highlight the competition between cavitation and stress-induced crystallization. Results show that the relative volume change does not exceed $6.10^{-2}$ in NR whereas it reaches $24.10^{-2}$ in F-NR. This is explained by the fact that fillers, which concentrate stress, are favorable to cavitation. The fact that no significant residual volume change is observed indicates that the mechanisms involved in volume variation are different from those that induce residual stretch. The full-field measurement method used in this study allows us to identify characteristic stretch ratios at the beginning of crystallization and at the end of crystallite melting. The difference in the kinetics of crystallization and crystallite melting explains the hysteresis loop observed between volume variation obtained during loading and unloading. The higher the hysteresis loop, the higher the difference in crystallization and melting kinetics. Here, fillers are found to minimize this difference. Finally, volume variation is stabilized after the second cycle and cyclic loadings do not influence the characteristic stretch ratios. The present work leaves some issues of importance unanswered, one of which is the comparison between the volume variation in crystallizable and uncrystallizable rubbers, especially under cyclic loadings. Further work in this field is currently being envisaged by the authors of this paper. 


\section{References and Notes}

(1) Gent, A. N.; Lindley, P. Proceedings of the Royal Society 1958, 195-205.

(2) Ball, R.; Doi, M.; Edwards, S.; Warner, M. Polymer 1981, 22, 1010-1018.

(3) Diani, J. Int. J. Fracture 2001, 112, 151-161.

(4) Flory, P. J.; Rehner, J. J. Phys. Chem. 1943, 11, 512-520.

(5) Payne, A. J. Appl. Polym. Sci. 1960, 3, 127-127.

(6) Trabelsi, S.; Albouy, P.-A.; Rault, J. Macromolecules 2002, 35, 10054-10061.

(7) Mullins, L.; Tobin, N. Rubber Chem. Technol. 1957, 30, 551-571.

(8) Christensen, R.; Hoeve, C. Rubber Chem. Technol. 1970, 43, 1473-1481.

(9) Penn, R. Rubber Chem. Technol. 1970, 14, 509-517.

(10) Shinomura, T.; Takahashi, M. Rubber Chem. Technol. 1970, 43, 1025-1035.

(11) Goebel, J.; Tobolsky, A. Macromolecules 1971, 44, 208-209.

(12) Gent, A. N.; Kawahara, S.; Zhao, J. Rubber Chem. Technol. 1998, 71, 668-678.

(13) Trabelsi, S.; Albouy, P.-A.; Rault, J. Macromolecules 2003, 36, 9093-9099.

(14) Poompradub, S.; Tosaka, M.; Kohjiya, S.; Ikeda, Y.; Tokiand I. Sics, S. J Appl. Phys. 2005, 97, 103529/1-103529/9

(15) Rault, J.; Marchal, J.; Judeinstein, P.; Albouy, P.-A. Macromolecules 2006, 39, 83568368.

(16) Toki, S.; Sics, I.; Ran, S.; Liu, L.; Hsiao, B.; Murakami, S.; Senoo, K.; Kohjiya, S. Macromolecules 2002, 35, 6578-6584.

(17) Miyamoto, Y.; Yamao, H.; Sekimoto, K. Macromolecules 2003, 36, 6462-6471. 
(18) Treloar, L. R. G. The Physics of Rubber Elasticity, 3rd ed.; Clarendon Press: Oxford.

(19) Dumoulin, S.; Tabourot, L.; Chappuis, C.; Vacher, P.; Arrieux, R. J. Mater. Process. Tech. 2003, 133, 79-83.

(20) Mullins, L. Rubber Chem. Technol. 1948, 21, 281-300.

(21) Le Cam, J.-B.; Huneau, B.; Verron, E.; Gornet, L. Macromolecules 2004, 37, 50115017.

(22) Gent, A. N. J. Appl. Polymer Sci. 1962, 6, 433-441. 


\section{List of figures}

Figure 1. Overall view of the optical setup

Figure 2. The first mechanical cycle in NR: (a) stress-stretch response, (b) volume variation

Figure 3. The first mechanical cycle in NR for prescribed stretch ratio inferior to $\lambda_{A}$ : (a) stress-stretch response, (b) volume variation

Figure 4. Tensile test stopped 1 min every $3 \mathrm{~mm}$

Figure 5. The first mechanical cycle in F-NR: (a) stress-stretch response, (b) volume variation

Figure 6. Influence of the kinetics of stress-induced crystallization on volume variation in both NR and F-NR

Figure 7. The first three mechanical cycles in F-NR: (a) stress-stretch response, (b) volume variation

Figure 8. The third mechanical cycle presented in Figure 7(b) 


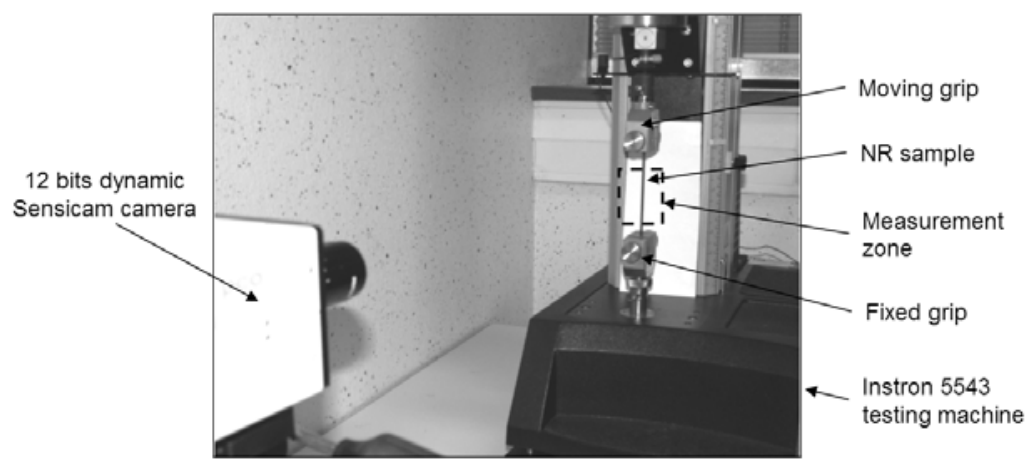

Figure 1

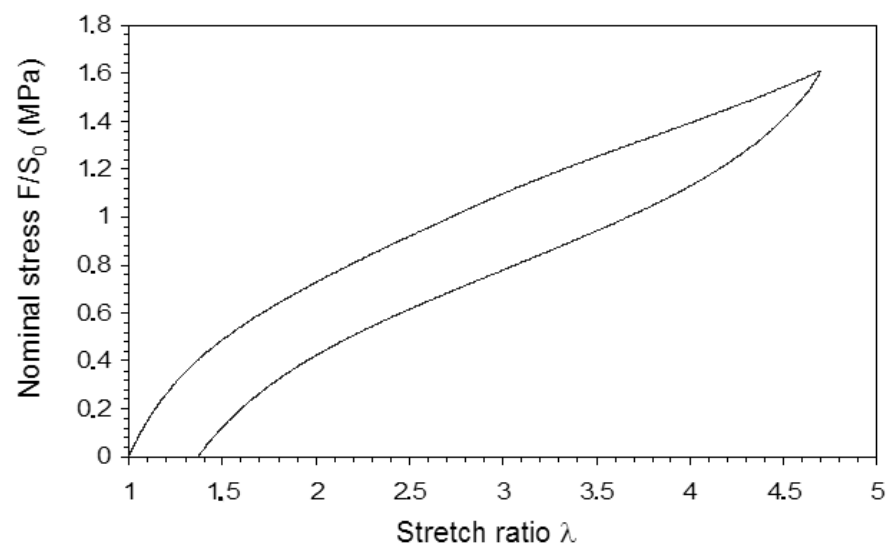

(a)

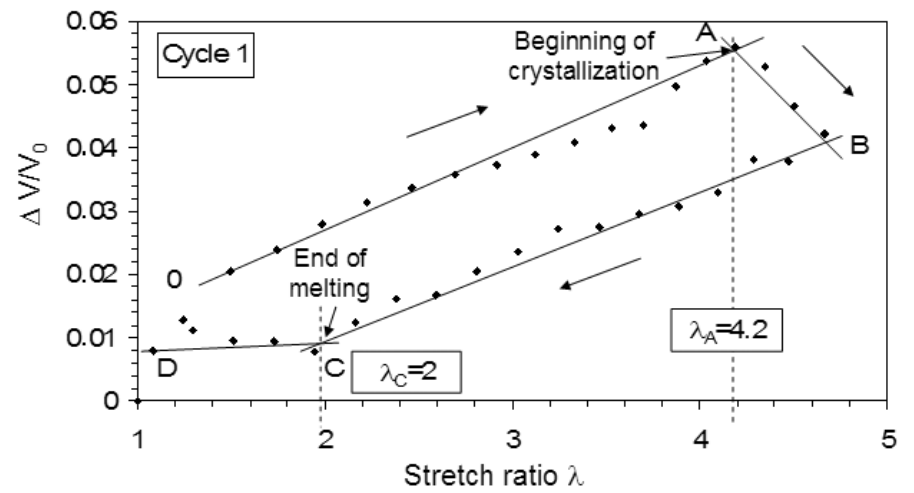

(b)

Figure 2 


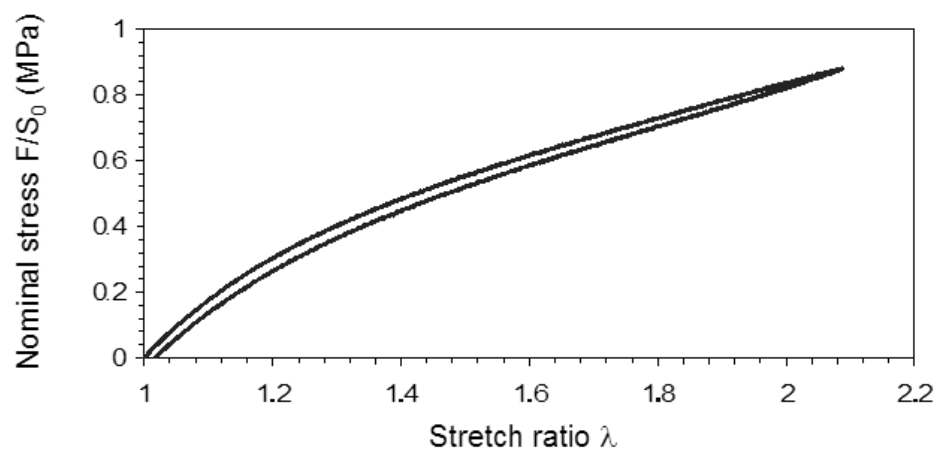

(a)

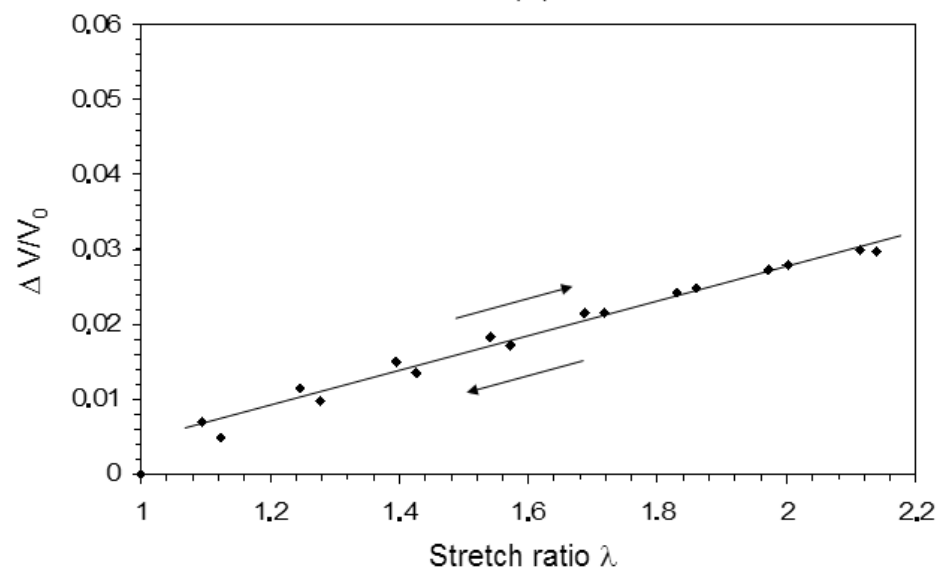

(b)

Figure 3

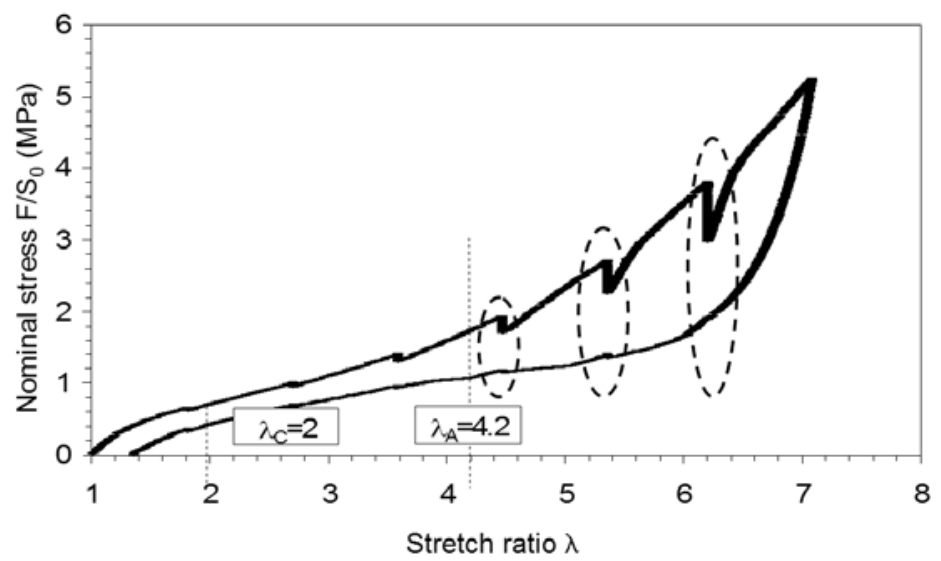

Figure 4 


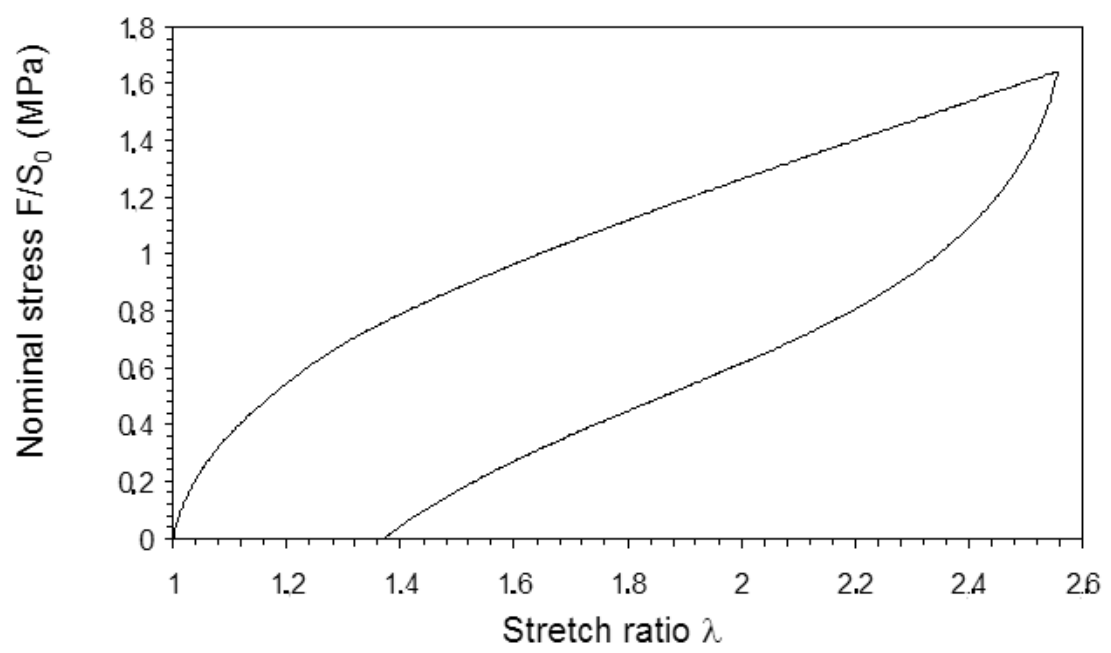

(a)

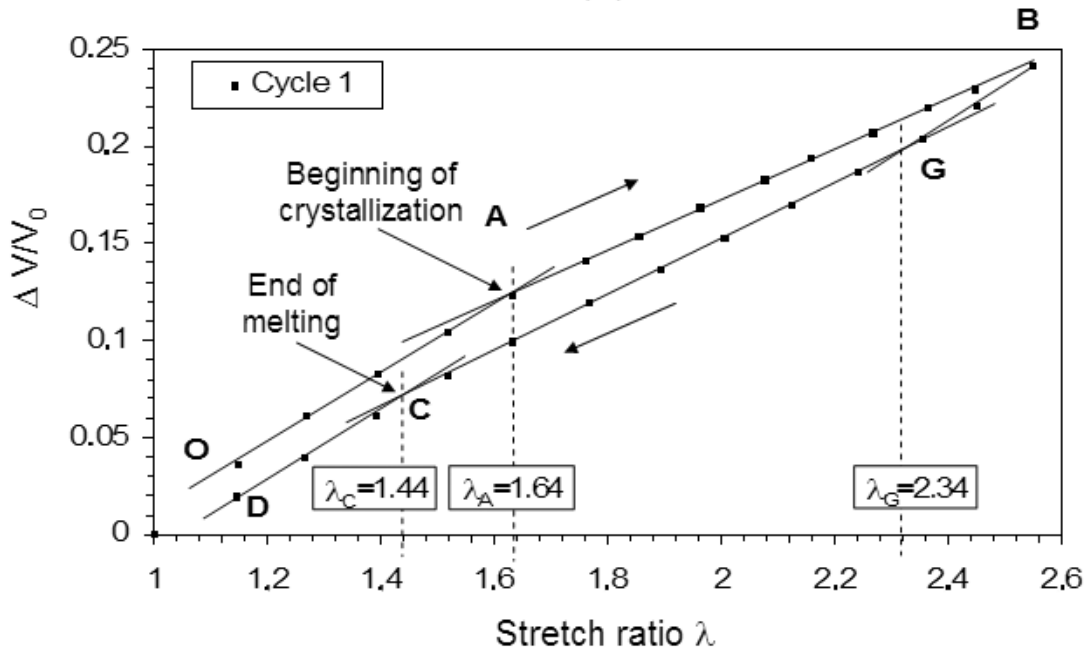

(b)

Figure 5 


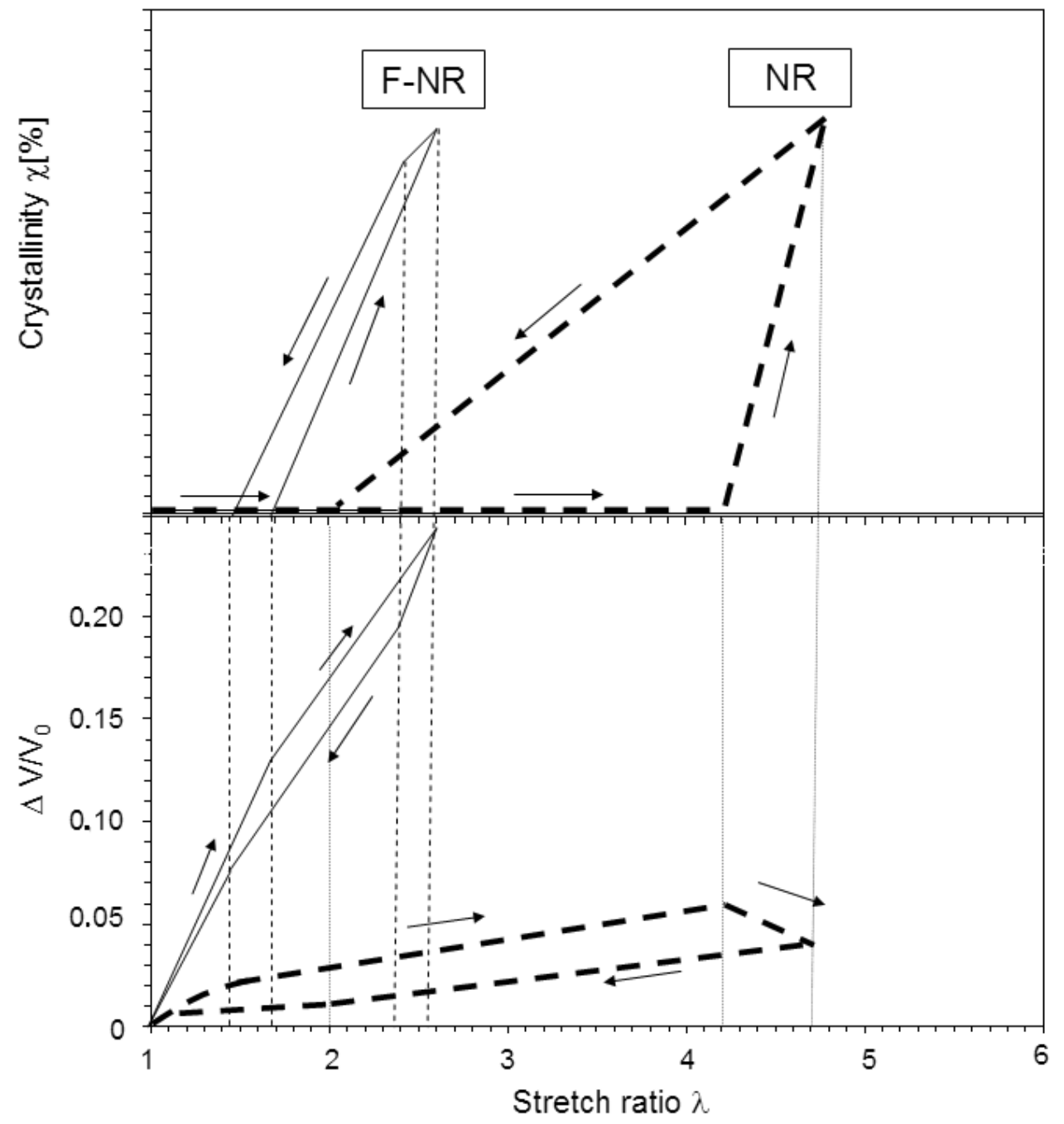

Figure 6 


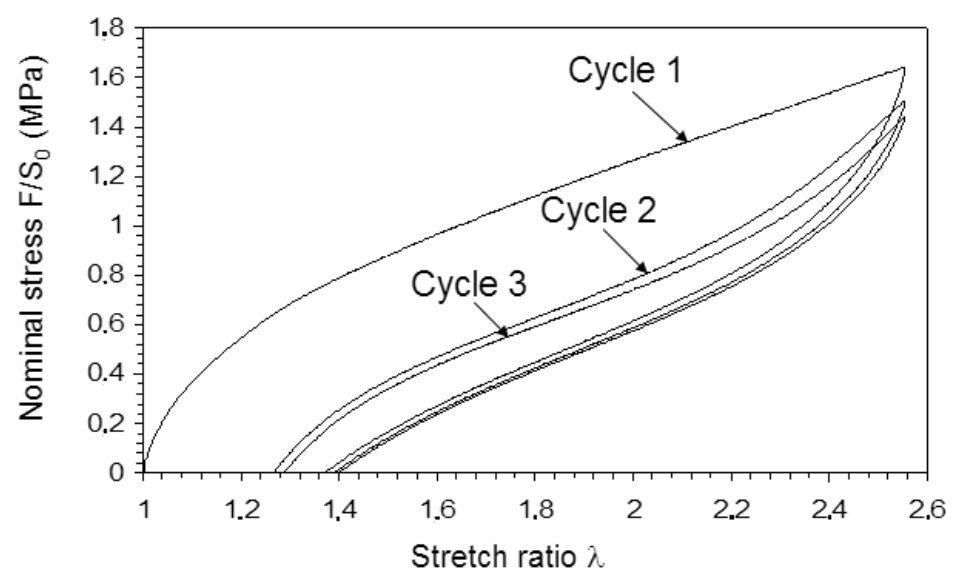

(a)

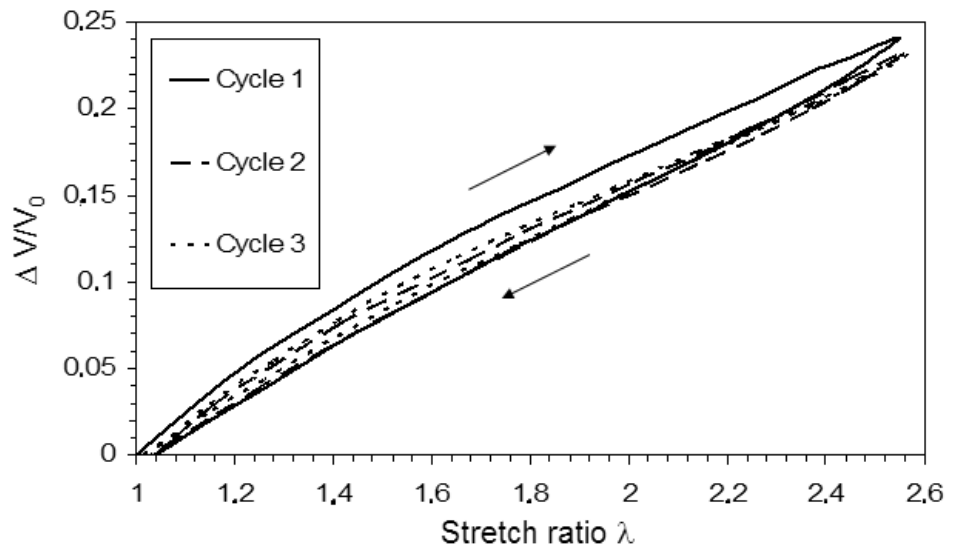

(b)

Figure 7

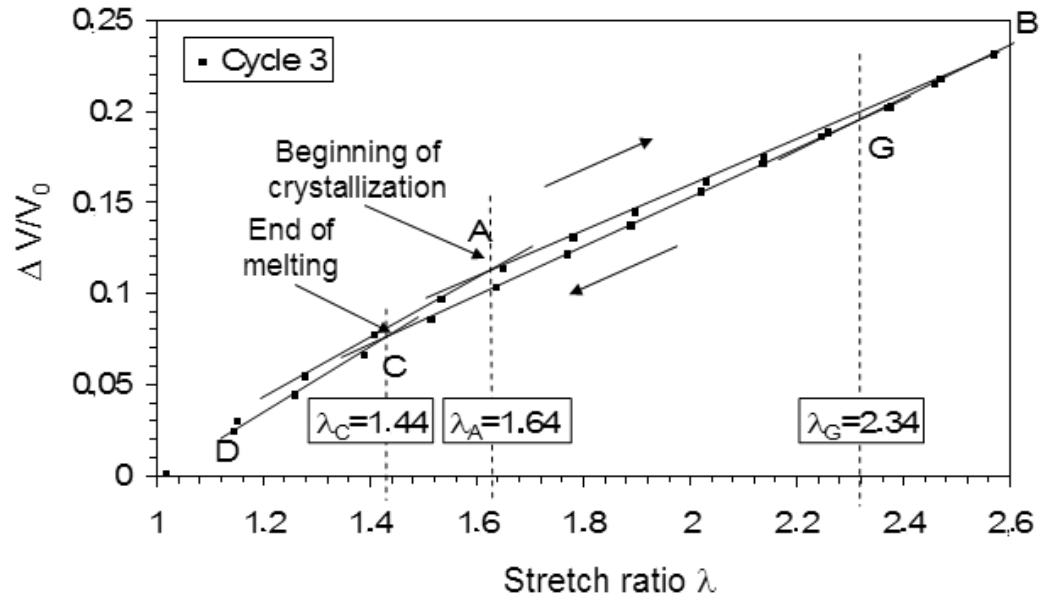

Figure 8 